
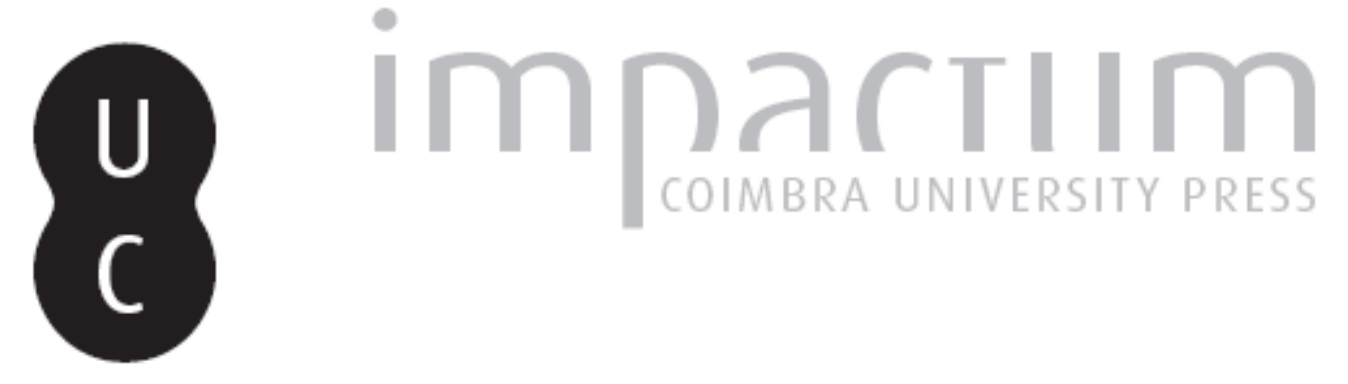

\title{
Do Estado Providência no feminino à história comparada das mulheres: a obra de Anne Cova
}

\author{
Autor(es): $\quad$ Pereira, Miriam Halpern
}

Publicado por: Imprensa da Universidade de Coimbra

URL

persistente:

URI:http://hdl.handle.net/10316.2/35454

DOI:

DOI:http://dx.doi.org/10.14195/0870-4147_45_29

Accessed : $\quad$ 26-Apr-2023 04:57:40

A navegação consulta e descarregamento dos títulos inseridos nas Bibliotecas Digitais UC Digitalis, UC Pombalina e UC Impactum, pressupõem a aceitação plena e sem reservas dos Termos e Condições de Uso destas Bibliotecas Digitais, disponíveis em https://digitalis.uc.pt/pt-pt/termos.

Conforme exposto nos referidos Termos e Condições de Uso, o descarregamento de títulos de acesso restrito requer uma licença válida de autorização devendo o utilizador aceder ao(s) documento(s) a partir de um endereço de IP da instituição detentora da supramencionada licença.

Ao utilizador é apenas permitido o descarregamento para uso pessoal, pelo que o emprego do(s) título(s) descarregado(s) para outro fim, designadamente comercial, carece de autorização do respetivo autor ou editor da obra.

Na medida em que todas as obras da UC Digitalis se encontram protegidas pelo Código do Direito de Autor e Direitos Conexos e demais legislação aplicável, toda a cópia, parcial ou total, deste documento, nos casos em que é legalmente admitida, deverá conter ou fazer-se acompanhar por este aviso.

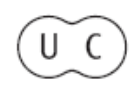




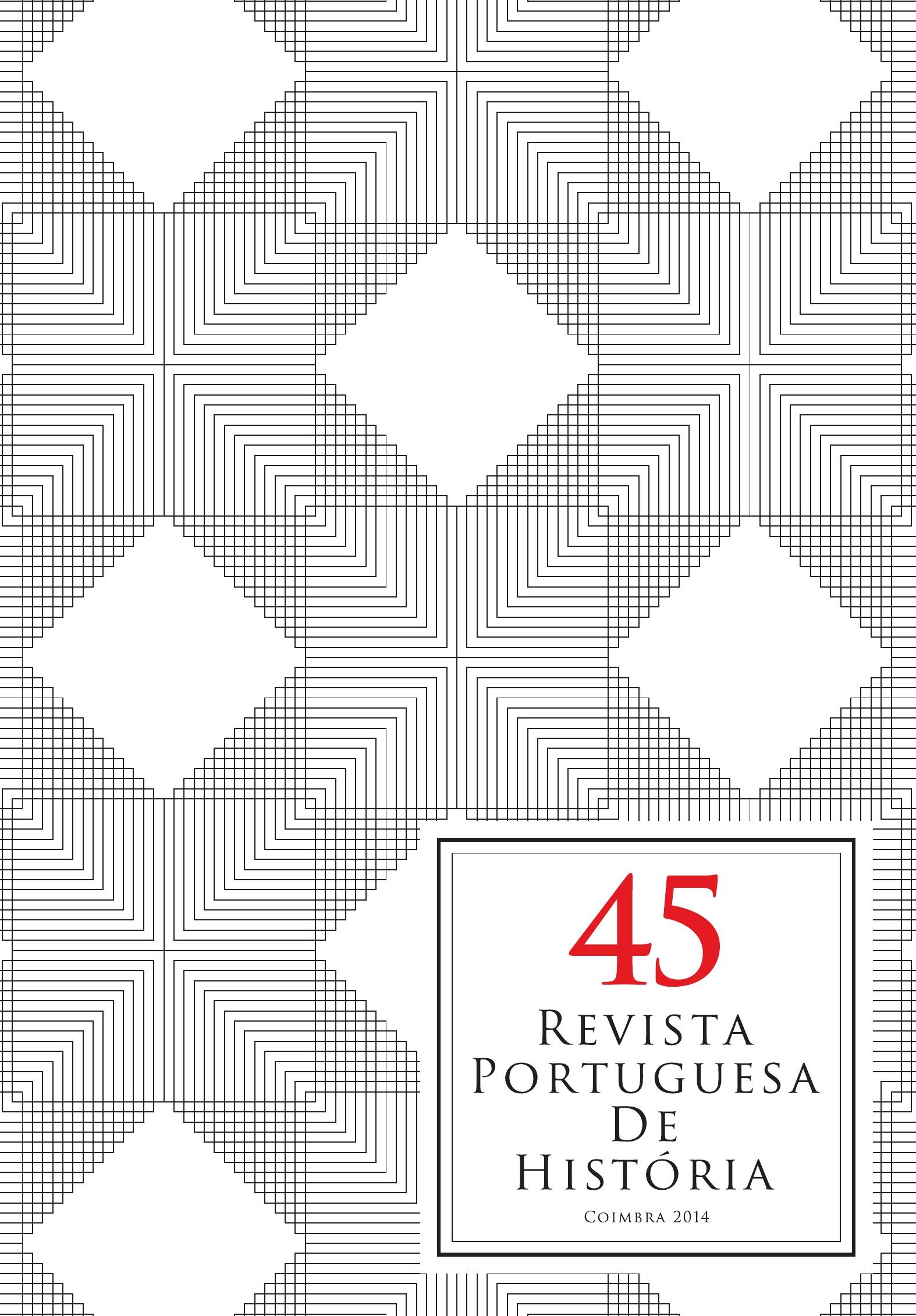




\section{Do Estado Providência no feminino à história comparada das mulheres: a obra de Anne Cova}

Anne Cova insere-se no movimento de cientistas sociais que vieram para Portugal de forma acidental e aqui acabaram por fazer a sua carreira, tornando-se parte da renovação das ciências sociais e da historiografia em Portugal. Em boa hora, veio enriquecer a historiografia sobre o género. A sua obra tem sido objecto de recensões e comentários em revistas internacionais de diversos países, mas no nosso país nada foi publicado a seu respeito. É mais do que tempo que o nosso meio científico, nomeadamente os seus elementos mais jovens, tomem consciência da relevante obra de Anne Cova.

Da sua carreira académica, parece-me importante destacar a sua colaboração durante nove anos no primeiro mestrado de estudos sobre a mulher, criado em Portugal, na Universidade Aberta em colaboração com Maria Beatriz Nizza da Silva ${ }^{1}$. Em linha com essa atividade lectiva, esteve a colaboração no PIUD com quatro seminários sobre história do género, enquanto investigadora do ICS, durante o ano lectivo transacto ${ }^{2}$.

Desde o inicio da sua carreira, Anne Cova optou pela investigação na área da história do género. Pertence a uma geração em que essa escolha se tornara possível graças ao caminho aberto precedentemente por historiadoras/es que introduziram a história do género nos curricula académicos, o que como se sabe, sucedeu na Europa com algum atraso em relação aos EUA. Esse trilho foi aberto por vezes por historiadoras/es que tinham iniciado o seu percurso no domínio da história social, em particular com estudos sobre a industrialização e as classes trabalhadoras, daí derivando o seu interesse acerca de grupos desfavorecidos ou marginalizados, como foi o caso de Pat Thane ou M. Perrot, coorientadora da tese de doutoramento de Anne Cova.

A obra de Anne Cova denota uma necessária filiação com a história social das classes trabalhadoras, uma vez que as mulheres trabalhadoras foram e são o objecto principal dos movimentos feministas. Mas a história do género é socialmente diversa, e as feministas são na sua maioria de proveniência bur-

${ }^{1}$ Desta colaboração conjunta, saliente-se a publicação de As mulheres e o Estado, Universidade Aberta, Lisboa 1999.

${ }^{2}$ Anne Cova é investigadora auxiliar no ICS-UL. Doutorou-se em História pelo Instituto Universitário Europeu de Florença (1994). Foi responsável científica do Arquivo de História Social do ICS-UL durante cinco anos (2006-2011). Actualmente, é vice-presidente da Associação Portuguesa de Investigação Histórica sobre as Mulheres (APIHM), filiada na International Federation for Research in Women's History (IFRWH). 
guesa. Este contraste sociológico entre o objecto do movimento feminista e a sua composição social dominante é uma questão central, a que voltarei mais adiante.

A dupla formação científica de Anne Cova, aliando a história à ciência política, favoreceu a sua capacidade de articular feminismos, movimentos sociais e a evolução política, vertente fundamental do seu trabalho. Insere-se na linha delineada por Karen Offen que mostrou como a história dos feminismos se deve enunciar no plural e constitui um domínio da história política. Contribuir para a história intelectual da política, em linha com P. Rosanvallon, é-nos anunciado logo no primeiro livro de Anne Cova, Maternité et droits des femmes en France (XIX.e-XX.e siècles), (Antropos1997), como sendo o objectivo orientador da sua reflexão e pesquisa. Muito em consonância também com Gisela Bock, orientadora da tese de doutoramento, cujos primeiros trabalhos se situavam justamente na confluência da história política e intelectual (esterilizações durante o nazismo).

Quando se pensa em história do género, ou se considera a vertente socioeconómica, ou se evoca a vertente política, e neste caso o que ocorre é o movimento sufragista, o combate pelo direito de voto feminino. Desde o início da década de 90, agulhando em sentido inovador, Gisela Bock e Pat Thane apontaram a relevância da maternidade na história dos feminismos. Leia-se : "a visão feminista da maternidade não representou a aceitação de um modelo tradicional da mulher, mas sim um apelo à sua reforma, para algumas até mesmo a revolução, em relação à situação das mães e das mulheres em geral. Em lugar de uma maternidade imposta, as mulheres tentaram controlá-la e melhorar as suas condições. Na realidade a identificação da mulher como mãe, função em que era insubstituível, proporcionou-lhe uma plataforma poderosa para fundamentar as suas revindicações de emancipação e reconhecimento social." Mesmo entre as sufragistas inglesas, como se sabe das mais combativas na Europa, existiu uma linha de argumentação maternalista: declaravam que era devido à sua especificidade como mães que precisavam de ter representação própria no aparelho político.

Numa época marcada pela constituição do Estado - Nação, a dimensão da população de cada país adquiriu particular importância. As preocupações com a queda da natalidade e o despovoamento apareceram mais cedo em França que noutros países. Neste contexto, o lobby natalista e também higienista, em relação com a mortalidade infantil e também com a ideia da defesa da qualidade da "raça" e do combate contra a degenerescência, estão na origem das medidas ditas de proteção do trabalho feminino. Na Alemanha, a proteção da maternidade, embora considerada como uma doença, esteve prevista desde os 
seguros bismarckianos. Mas não em França, apesar da forte acção do lobby natalista. $\mathrm{O}$ caminho foi longo e complexo e um dos principais entraves residiu no conflito entre as esferas privada e pública. É esse longo percurso e os seus meandros que Anne Cova estudou de forma exaustiva.

Maternité et droits des femmes en France (XIX.e-XX.e siècles), (Antropos1997), expressivo título do primeiro livro já referido, constitui o eixo central, completado depois por dois livros em que se abordam separadamente as duas correntes minoritárias dentro do feminismo francês da época, o movimento católico e o movimento anarquista. A reflexão teórica bem fundamentada e inovadora percorre o conjunto da sua obra, pondo em relevo o interesse do enorme trabalho empírico realizado. Como é aconselhável na pesquisa histórica, cruzou diversas fontes, debates parlamentares, impressa geral e impressa feminina, documentação de arquivos públicos e de arquivos privados. Da sua tese de doutoramento original nasceram três livros, o que mostra o impressionante trabalho que efetuara logo de início. Publicados com longos intervalo entre si, beneficiaram de cuidada reformulação e atualização.

A opção de situar a sua pesquisa num tempo longo, cerca de meio século, é a mais adequada à compreensão do processo no seu conjunto. Os critérios políticos e ideológicos, subjacentes à escolha dos marcos cronológicos, são justificados com clareza e realçam a relevância do enquadramento político. Também por isso esses marcos cronológicos divergem ligeiramente nestes três livros. A complexidade dos debates, essencial na sua obra, nunca é evitada. Um traço comum é a vontade de deslindar os vários matizes nas atitudes estudadas, evitando simplificações e sínteses fáceis. É um prazer ler Anne Cova, escreve bem, expondo de forma clara e bem estruturada as suas reflexões.

O papel da maternidade na definição dos direitos das mulheres e a construção do Estado providência é o tema do primeiro livro. Caracteriza-o uma análise sistemática e exaustiva do tema, repartida em três fases. Da sua conclusão ressalta o papel das feministas que se unem nalguns pontos essenciais apesar das suas divergências profundas, contribuindo decisivamente para a construção do Estado Providência, adoptando a dominante táctica reformista dos pequenos passos. Nas margens, estão os moderados e os radicais. Os homens políticos, parlamentares e ensaístas, intermediários ou mediadores fundamentais, mostraram um grau de permeabilidade variável. O lobby natalista tem evidentemente um papel fundamental. Nesta evolução destaca-se uma mutação essencial, a substituição da concepção da maternidade enquanto doença para fundamentar as medidas de proteção, pelo reconhecimento da sua função social. Paralelamente, ao ciclo da assistência sucede-se o ciclo do seguro nos anos 30, que, conforme aponta, sucede à anterior afirmação do direito à assistência. 
Face a tudo isto, Anne Cova demonstra como a emergência do Estado Providência constituiu um resultado de um agregado de soluções particulares, para o qual as associações das mulheres contribuíram. A visibilidade destas associações só emergiu do seu trabalho analítico, pois como diz, a argumentação dos parlamentares feministas retoma com frequência a argumentação das feministas, sem nunca as citar, porventura devido à incerta conquista da respeitabilidade por parte destas associações.

A relação entre a história da religião e a história da mulher constituía terreno pouco abordado antes da publicação do segundo livro de Anne Cova, $A u$ service de l'eglise, de la patrie et de la famille, (L'Harmattan, Paris, 2000). Mediante ampla investigação em arquivos privados, a autora descobre a variedade das associações femininas intervenientes na esfera pública e a sua diversidade de atitudes. A conciliação parcial entre a política natalista e a defesa dos direitos das mulheres é uma das conclusões deste livro. Mas conciliação só parcial, porque a divergência afirmava-se face ao divórcio, o direito de trabalho fora de casa e os direitos políticos das mulheres, e até o próprio Caso Dreyfus, revelando-se uma atitude antissemita entre as mulheres católicas.

De algum modo no outro extremo, situava-se a defesa da liberdade da maternidade, então defendida principalmente pelo movimento anarquista, em que as mulheres tinham presença: é o objecto de Féminismes et neo-malthusianismes sous la III.e République: "La liberte de la maternité" (L'Harmattan, Paris, 2011). A teoria neo-maltusiana é um dos suportes deste grupo, que defende a liberdade de escolha de ser mãe ou não, criticando o modelo imperativo predominante. Em contraste, não parece que em Portugal o movimento feminista tem tido qualquer relação com este tipo de atitudes ${ }^{3}$. Na época eram atitudes rejeitadas pela sociedade, tanto mais que estavam associadas à valorização da vida sexual. Em consonância com o movimento anarquista, este grupo feminista vai rejeitar numa fase inicial o contacto com o meio parlamentar e critica as feministas apelidadas de burguesas. Depois da lei de 1920 que proíbe o aborto e a propaganda anticoncepcional, a sua situação torna-se difícil e até perigosa. Do combate deste grupo minoritário contra a lei iníqua de 1920 advieram perseguições, julgamentos e prisões: o pedido de revocação desta lei percorre de forma insistente a imprensa deste grupo. neste Nos anos 30 , este grupo acaba por aceitar uma aproximação com o meio parlamentar e finalmente com o próprio movimento feminista reformista. Conseguiriam até influenciar um político importante, como Léon Blum. Contudo, uma vez no

\footnotetext{
${ }^{3}$ Lousada, M. Alexandre e Freire, João org. Greve dos Ventres! Lisboa, Colibri, 2012
} 
poder, Léon Blum não anularia as leis de 1920-23, isso demoraria ainda algumas longas décadas até acontecer e mais uma vez a intervenção das mulheres foi fundamental.

Voltando ao grupo neomalthusiano, este foi um combate percursor que embora minoritário na sua expressão, esteve curiosamente mais em consonância com o comportamento real da população. Como conclui a autora, a natalidade não se decreta: a legislação protetora da maternidade e do trabalho feminino não permitiu contrariar o decréscimo da natalidade e da população. Neste sentido, surpreende a inexistência de qualquer alusão à imigração, justamente promovida desde o final do século XIX para fazer face a esta situação.

A autora aponta também com razão as consequências negativas a médio prazo das leis protetoras da maternidade, que acabaram por dificultar a integração no mercado de trabalho, entre outros motivos pelo encarecimento do trabalho feminino, questão pertinente e atual, que está longe de estar resolvida nos nossos dias.

No conjunto dos três livros afirmam-se três tipos de intervenientes na construção da cidadania social feminina. As associações femininas e feministas, de proveniência burguesa, os parlamentares e ensaístas, ou seja a elite política, e o próprio Estado. São as atitudes destes atores que desvendou nestes livros, não as realizações concretas. A construção da cidadania feminina é inserida no debate acerca da sequência entre direitos civis, direitos políticos e direitos sociais, propondo a revisão da cronologia defendida por T.H. Marshall. É finalmente a concepção de democracia, salienta a autora que se revela na forma diferente como as mulheres e os homens acedem à cidadania. A cidadania social, como é sabido, precedeu a cidadania política em França, como também na Alemanha. E aliás em certa medida também em Portugal, como tive ocasião de o salientar recentemente ${ }^{4}$. No caso francês, Anne Cova cita Caroline Pateman para o explicar: teria sido impossível defender simultaneamente a cidadania e a diferença. Na realidade parece-me constituir mais uma constatação do que uma explicação. A verdade é que a dominante atitude reformista dos pequenos passos, na qual acabam por se envolver os diferentes feminismos, beneficiou da "boleia" do forte lobby natalista. Por outro lado, o movimento sufragista feminino foi débil se comparado com a Inglaterra e com

\footnotetext{
${ }^{4}$ Pereira, Miriam Halpern “A questão social na I República: alguns aspectos “ in Congresso Internacional I república e o republicanismo. Atas, Assembleia da República, Lisboa, 2012, pp.357-370
} 
os EUA. Não se deve às características dos próprios feminismos franceses o preterir do direito de voto? Em Portugal em parte foi assim.

Uma questão omissa nesta obra e também de um modo geral com frequência, talvez pela sua incomodidade, prende-se com o contraste sociológico entre o objecto do movimento feminista e a própria origem das feministas, na sua maioria de origem burguesa. Como se sabe, as feministas foram vivamente hostilizadas pelo movimento operário, pelos socialistas e comunistas, em termos gerais. Claro que houve excepções, mas essa é uma situação de conflito grave que perdurou e é ainda um assunto mal conhecido.

A observação genérica de Anne Cova, a propósito da integração de sucessivas medidas anteriores na segurança social moderna, no pós-2. ${ }^{a}$ Guerra mundial, dizendo que isso mostra que as políticas sociais não são construídas sobre o vácuo, mas pelo contrário se baseiam em experiências anteriores, é muito pertinente e não deve ser esquecida. E aí também o caso português é disso um bom exemplo, apesar das dramáticas mudanças políticas ao longo do século XX.

A porta da história comparada da história de género perspectivou-se rapidamente para Anne Cova como inevitável, terminada a sua obra sobre o caso francês. Só quando o conhecimento dos casos nacionais tivesse atingido um certo limiar, seria possível enveredar por este caminho. E a sua geração encontrou também aqui o terreno desbravado pela geração precedente de historiadoras/es. O livro organizado com Gisela Bock, Écrire l'Histoire des Femmes en Europe du Sud, XIX-XX.e siècles(Celta, Oeiras, 2003) reúne estudos sobre a historiografia do género em vários países e consiste ainda no colocar lado a lado de casos nacionais. Desafio da comparação (Celta, Oeiras, 2004) em Portugal e no Brasil, organizado com Natália Ramos e Teresa Joaquim, compreende alguns ensaios de comparação temáticas de ambos lados do Atlântico. Mas, é com a História comparada das mulheres: novas abordagens, (Lisboa 2008), tradução de Comparative Women's History: New Approaches (EUA, 2006), mais recentemente traduzido em francês (ENS Éditions, 2009), que se dá um salto qualitativo decisivo. Anne Cova reúne neste livro quatro estudos de historiadoras prestigiadas (Karen Offen, Bonnie S. Anderson, Ann Taylor Allen e Susan Pedersen), nos quais são debatidos os parâmetros metodológicos da história comparada neste domínio.

Uma excelente introdução de Anne Cova permite conhecer a evolução em curso, começando pelas grandes obras fundadoras que proporcionam uma visão continental ou mesmo mundial da história das mulheres nas suas diferentes vertentes, os dicionários e as enciclopédias, proporcionando ao público uma excelente bibliografia comentada. Destas iniciais visões globalizantes, 
foram nascendo perspectivas temáticas comparadas, em torno de questões diversas. Estado Providência, legislação laboral e "protecionista", os movimentos de mulheres, os feminismos, fascismo e feminismo, são alguns dos tópicos evocados. $\mathrm{Na}$ abordagem de qualquer destes temas as historiadoras encontraram-se diante de problemas metodológicos similares, desde a escolha do tipo de fontes e a dificuldade de encontrar fontes comparáveis, ao inevitável recurso também a fontes secundárias, colocando a historiadora comparatista face ao frequente desencontro de perspectiva nas historiografias nacionais. Essencial é, sublinha Anne Cova, a clara definição dos termos da comparação : Il est capital de disposer de catégorisations, de définitions et de typologies appropriés si l'on veut établir des comparaisons solides.... Le grand avantage de ces catégorisations est de rendre des comparaisons possibles, de tendre à une clarification conceptuelle, de disposer d'outils d'analyse, de dégager des grandes tendances.

Os escolhos podem principiar ao nível da própria linguagem e a tradução. As diferenças linguísticas constituem uma fronteira nacional delicada, como salienta, citando o exemplo escolhido por Ann Taylor Allen: se em francês e em português um único termo "maternidade" tem vários significados, em alemão temos Mutterschaft, para a maternidade biológica, e Mutterlichkeit, para o sentimento maternal. E em inglês existem também duas palavras, motherhood e maternity.

Nas comparações realçam-se mais as diferenças que as semelhanças, essa é uma das suas contribuições. Para a autora, apesar das múltiplas dificuldades da história comparada, a descoberta de novas questões que a análise de casos únicos nunca permitiria conhecer, constitui inestimável contribuição desta metodologia na historiografia das mulheres, como em geral. É neste tipo de abordagem que apostou no seu atual projeto sobre os Conselhos Nacionais das Mulheres de quatro países, Brasil, França, Itália e Portugal de que os primeiros resultados foram publicados in "Feminisms and Associativism : the national councils of women in France and Portugal, a comparative historical approach, 1888-1939" in Women's History Review, v.22, 1-2013.

Anne Cova tem participado em vários projetos internacionais e procedido à difusão do seu trabalho científico em inúmeros artigos e participações em colóquios $^{5}$. A sua colaboração em vários livros internacionais dirigidos por historiadoras prestigiadas, assim como as recensões à sua obra publicadas em

\footnotetext{
${ }^{5}$ Entre os artigos publicados em revistas portuguesas salente-se "Génese do Estado Providência em França. A protecção da maternidade e os movimentos de mulheres (1892-1939)" Ler História, 37, "Salazar e as mulheres: uma abordagem comparativa" (em colaboração) Pénelope,17.
} 
revistas científicas internacionais, atestam o grande apreço de que tem sido objecto. Espero ter contribuído para a difusão da sua obra também em Portugal. As /os especialistas naturalmente conhecem-na. Mas o que está na agenda atualmente é a integração da história das mulheres e do género na História em geral.

Miriam Halpern Pereira 